\title{
Effect of aggressive pH media on peat treated by cement and sodium silicate grout
}

\begin{abstract}
The effects of aggressive peat nature $(\mathrm{pH})$ on the strength of peat treated by cement and cement-sodium silicate grout were investigated by evaluating the changes in unconfined compressive strength, moisture content, and scanning electron microscopy (SEM) of samples with time in different $\mathrm{pH}$ media. The results indicate that peats treated by cement-silicate have higher strength than peats treated by cement, due to an increase in $\mathrm{pH}$ value of the media. Furthermore, cement and cement-silicate are highly effective in reducing the moisture content and void ratio of the treated peats. The microstructures of treated peats support the laboratory test results.
\end{abstract}

Keyword: Peat; Aggressive pH media; Cementation; Sodium silicate; Grout; Microstructure 